Communal orientation, benefit-finding, and coping among young carers

\author{
Areguy, Fistum \\ University of Guelph \\ Steven E. Mock \\ University of Waterloo \\ Andrea Breen \\ University of Guelph \\ Tricia van Rhijn \\ University of Guelph \\ Kimberly Wilson \\ University of Guelph \\ Donna S. Lero \\ University of Guelph
}

Note: This is an Accepted Manuscript of an article published by Taylor \& Francis in Child and Youth Services on May 30, 2019, available online:

http://www.tandfonline.com/10.1080/0145935X.2019.1614906. 


\begin{abstract}
A substantial body of research documents the impact of informal care on adult caregivers' wellbeing, but little is known of the experiences of young carers who attend postsecondary schools in Canada. Despite the estimated 1.25 million young people ages 15-24 assuming caregiving roles in Canada, young carers are a hidden and largely unsupported demographic in Canada. To gain a better understanding of young caregiving in Canada, the current study explores the role of communal orientation, benefit-finding, life satisfaction, and family satisfaction among young student carers. Further, we examine the mediating role of diverse coping strategies to better understand how communal orientation may be associated with wellbeing. One hundred and thirty-seven participants were recruited from two Canadian universities, and data were collected through online surveys. Results showed that while communal orientation and the use of coping strategies were positively associated with benefit finding, communal orientation was negatively associated with life satisfaction and family satisfaction. Use of instrumental support mediated the association of communal orientation with benefit finding. The findings suggest a communal orientation may help young carers find benefit in the caregiving role by enhancing the use of instrumental support coping strategies.
\end{abstract}

Keywords: benefit-finding; communal orientation; coping; informal caregiver; postsecondary; wellbeing; young carer 


\section{Communal orientation, benefit-finding, and coping among young carers}

As a caregiver for my grandfather, I was the one to know all his medications and when he had to take them ... I was up with him late at night giving him [medication] when he had an anxiety attack and then staying with him until he fell asleep. It prevented me from being fully and properly rested for school or from completing my work to the best of my ability. There were negative effects of me having to care for him, but it brought me closer to him. (Sue, age 18)

In 2012, nearly half of all Canadians ages 15 and older reported having provided some level of caregiving for a friend or family member with a health condition, disability, or agingrelated needs at some point in their lives (Sinha, 2013). While these numbers may be surprisingly high, they are expected to increase considerably with demographic trends toward an aging population (Fast, 2015). Although most informal care is provided by working-age and older adults, young family members like Sue (paraphrased above), an 18-year-old participant in our research with young carers, also take on care-related responsibilities. "Young carers" are defined in the wider literature as young people, typically under the age of 25 , who provide substantial unpaid caregiving for another person that goes beyond that which is normally expected of someone their age (Aldridge \& Becker, 1993; Becker, 2007; Miller, 2012; Remtulla, Charles, \& Marshall, 2012; Rose \& Cohen, 2010), though what is normally expected differs greatly when considering socio-cultural differences in understandings of caregiving responsibilities (Andreouli, Skovdal \& Campbell, 2013; Skovdal \& Andreouli, 2011; Skovdal, Ogutu, Aoro, \& Campbell, 2009).

According to Stamatopoulos's (2015a) research using Canadian census data, in 2006 there were 1.18 million caregivers ages 15-24 who provided some form of unpaid care to a family member or friend with a long-term health condition, disability, or aging needs. The most recent data on caregivers in Canada from the 2012 General Social Survey (GSS) highlighted that the number of young carers ages 15-24 grew to 1.25 million (Stamatopoulos, Forthcoming). However, the actual number of young carers is undoubtedly even higher since the available statistics do not include young people ages 5-14 who provide unpaid care and who likely represent the most vulnerable cohort (Stamatopoulos, 2015a). The 2012 GSS revealed that grandparents $(48 \%)$ were the most common care recipients of young carers' help, followed by parents, in-laws, and family members (38\%) (Battams, 2013).

Despite the prevalence of young caregiving in Canada, there is very limited national awareness of young carers and no dedicated legislative supports (Stamatopoulos, 2015b). This is a concern given the number of young carers will likely increase with current demographic trends, includ ing an aging population, the rising numbers of children born to older parents, and a trend toward multi-generational living (Stamatopoulos, 2015b). The increasing participation of women in the workforce is also having an impact on the number of young carers, with younger generations perhaps required to assume responsibilities for caregiving that have traditionally 
been carried out by women in the home (Stamatopoulos, 2015b). Young carers are a hidden demographic and most are never identified by service providers, educators, or others who might provide resources and support (Ali, Ahlström, Krevers, Sjöström, \& Skärsäter, 2013; Banks et al., 2002).

Research on young carers suggests the caregiving experience has significant and unique impacts on individual and social aspects of wellbeing. These impacts can include negative consequences for young carers' physical health (Hill, 1999); social isolation and psychological distress relating to worries about the health of the person for whom they provide care; and anger, resentment and emotional exhaustion (Aldridge \& Becker, 1993; Armistead, Klein, \& Forehand, 1995; Banks et al., 2002; Charles et al., 2012; Cree, 2003; Frank, 1995; Hill, 1999; Worsham, Compas, \& Ey, 1997). Though individual needs vary widely in relation to specific caregiving relationships (Thomas et al., 2003), caring for longer durations and from a young age is highly related to more negative young carer outcomes (Charles et al., 2012). Stamatopoulos (2018) has recently coined the term "young carer penalty" to acknowledge the range of "personal (emotional, familial, and social) and professional (i.e., educational and employment-based) penalties incurred by youth's substantial and ongoing caregiving" (Stamatopoulos, 2018, p. 11).

Studies on coping and adjustment among adult caregivers have demonstrated that the degree of social support and quality of relationships play an important role in moderating caregiver health and wellbeing (Brown, 2007; House, Landis, \& Umberson, 1988; Pinquart \& Sorensen, 2003a,b; Schulz, O’Brien, Bookwala, \& Fleissner, 1995; Schulz \& Sherwood, 2008; Vitaliano, Zhang, \& Scanlan, 2003). The availability of social resources such as informal support from family, friends, and partners, as well as formal support services for young carers, is especially important and has been found to be highly predictive of adjustment and positive outcomes (Aldridge \& Becker, 1993; Barry, 2011; Cassidy \& Giles, 2013; Cassidy, Giles \& McLaughlin, 2014; Early, Cushway, \& Cassidy 2006; Pakenham, Bursnall, Chiu, Cannon, \& Okochi, 2006; Smyth, Blaxland, \& Cass, 2011). Though there is some Canadian research on young carers in high school settings (Charles et al., 2010), there is no published research that examines young carers in postsecondary settings in Canada. While postsecondary education presents most young people with challenges and stress (e.g., Adlaf, Demers \& Gliksman, 2005; Adlaf, Gilksman, Demers, \& Newton-Taylor, 2001), caregiving may add to the challenges that young adults face as they pursue postsecondary education.

To better understand the associations among social contexts, relationship elements, and young carer outcomes, this article examines the association of communal orientation with benefit-finding, life satisfaction, and family satisfaction among postsecondary students who provide varying degrees of informal care. The article will first describe the guiding theoretical frameworks that formed our research questions will then outline the methods and results of our study. The article will conclude with a discussion of the findings and recommendations for future research directions. 


\section{Caregiving and Communal Orientation}

While there are clearly negative impacts associated with caring from a young age, studies have also shown that there are potential relational benefits to early caregiving experiences. Young carers report a greater sensitivity to others' needs, increased levels of altruism and compassion, and closeness to their care recipients (Aldridge \& Becker, 1993; Banks et al., 2002; Becker, 1995; Charles et al., 2012; Grossman, 1972). Research on adult caregiving points to the reciprocity and closeness in the caregiving relationship as well as positive meaning associated with caring as being instrumental for caregiver wellbeing (Cohen, Colantonio \& Vernich, 2002; Fast, 2015; Fauth et al., 2012).

The impacts of caregiving are variable. While some young carers may be especially vulnerable to negative life outcomes because of the nature of their caregiving role, relationship factors, or other variables within or outside the caregiving relationship, others may thrive as carers and in their lives beyond this role. Clark and Mills's (1979, 2012; Mills \& Clark, 1982) approach to "relationship orientation" may be used as a guiding theoretical framework to help to explain these differences. Research on relationship orientation identifies two distinct dispositions toward helping relationships: exchange orientation, which is an expectation of direct benefit or pay for labor or service, and communal orientation, which is concern about others' needs and an increased feeling of responsibility for meeting those needs. While research has shown communal orientation is linked to resilience among adult caregivers and can buffer burnout and depression related to caregiving demands (VanYperen, Buunk, \& Schaufeli, 1992; Williamson \& Schulz, 1990), a handful of studies have found that when there is a per ceived inequity within a specific relationship context, communal orientation is linked to burnout among caregivers (Truchot \& Deregard, 2001; Truchot, Keirsebilck, \& Meyer, 2000). Based on research that links communal orientation to qualities such as emotional expressiveness (Clark \& Finkel, 2005), prosocial behavior and high-quality relationships (Jones \& Vaughan, 1990; McCall, 1995; Thompson \& DeHarpport, 1998) and personal resources through the experience of positive emotion (Le, Impett, Kogan, Webster \& Cheng, 2013), it is likely that highly communally oriented young carers who are in socially supportive relationships may experience positive effects, especially when they are able to provide help that effectively addresses the needs of their care recipients. Although we could find no published studies that examine the role of communal orientation among young carers, the literature that identifies social supports and relationship quality as vital to positive young carer outcomes (Barry, 2011; Moore, McArthur, \& Noble-Carr, 2011; Pakenham et al., 2007; Smyth et al., 2011) suggests that communal orientation could have implications for a global assessment of wellbeing and social implications for young carers.

\section{Caregivers Use Benefit-Finding}

Psychological and social resources play a crucial role in young carers' coping abilities (Cassidy \& Giles, 2013; Cassidy et al., 2014; Early et al., 2006; Pakenham et al., 2007). Previous research on coping has discerned three types of responses: dealing with the problem that is causing the distress (problem-focused coping), reducing the distress emotions caused by the 
problem (emotion-focused coping), and avoiding any acknowledgement that the problem exists (avoidance coping) (e.g. Carver \& Vargas, 2012).

The extent to which individuals can adapt to stressful situations and adversity is influenced, in large part, by their ability to make sense of or find meaning in their experience. Park and Folkman's (1997) theoretical analysis of the role of meaning-making in stress and coping highlights how reappraisal processes can affect the global meaning and situational meaning of an event. Research suggests benefit-finding as a key construct of coping (Davis, Nolen-Hoeksema, \& Larson, 1998) may be conceptualized as a cognitive reappraisal coping strategy that may help people reduce or manage negative outcomes in response to life-altering or negative events (Affleck \& Tennen, 1996; Taylor, 1983).

Studies on adult caregivers have shown that benefit-finding consistently relates to positive health outcomes in both adult carers and care recipients (Kim, Schulz \& Carver, 2007) and is an effective moderator of stressful outcomes related to giving and receiving care. Benefitfinding has been shown to predict psychological wellbeing among patients diagnosed with multiple sclerosis (MS) and their caregivers (Pakenham, 2005), better adjustment to stress among parents of children with autism (Pakenham, Sofronoff, \& Samios, 2004), and lower levels of distress for people coping with the death of a family member (Davis et al., 1998). In a study examining meaning making, benefit-finding and depressive symptoms among caregivers and patients with Amyotrophic Lateral Sclerosis (ALS), Mock and Boerner (2010) found benefitfinding to be a key buffer of stress among both patients and caregivers.

\section{Young Carers and Benefit-Finding}

There are many reports of young people who experience a range of positive outcomes associated with their caregiving responsibilities (Charles et al., 2012; Clay, Connors, Day, Gkiza \& Aldridge, 2016; Pakenham et al., 2006; Thomas et al., 2003). In the opening words, "Sue" (paraphrased) provides an example of a young caregiver facing challenges while also finding relational benefits. She says of her relationship with her grandfather: "There were negative effects of me having to care for him, but it brought me closer to him."

The limited research examining benefit-finding among young carers has produced similar findings to research with adult caregivers. Pakenham et al. (2007) found that among young carers ages 10-25, benefit-finding was strongly correlated to the coping strategies of acceptance, problem solving, and seeking social support. Cassidy and Giles (2013) identified a benefitfinding dimension within The Young Carers Perceived Stress Scale (YCPSS) (Early et al., 2006) and found that in a sample of young carers ages $12-18$, benefit-finding not only buffered high levels of burden but also was predictive of positive health outcomes and inversely related to negative health outcomes (Cassidy et al., 2014). Cassidy et al. (2014) also found social recognition of the young carer role and support from family was closely related to higher levels of benefit-finding, and resilience and positive coping correlated with benefit-finding. In light of these findings, we hypothesized benefit-finding would be an important factor in young carers' experiences of caregiving and coping among those engaged in postsecondary education. 


\section{Research Questions}

The aim of this exploratory study was to examine the experiences of young carers attending university to gain a better understanding of how relationship orientation and coping variables interact and affect young carer outcomes. The following questions guided this investigation:

1. What is the association between communal orientation and benefit-finding among young carers attending postsecondary institutions?

2. How does communal orientation and the use of coping strategies impact young carers' wellbeing while at school?

Based on adult caregiver research, we hypothesized communal orienta tion and benefitfinding would be positively associated among young carers, and that association would be mediated by young carers' use of coping strategies in school. Our second research question focused on life and family satisfaction as key outcomes of wellbeing among young carers. Given the findings that communal orientation has a positive effect on caregiver wellbeing (VanYperen, Buunk, \& Schaufeli, 1992; Williamson \& Schulz, 1990), we predicted higher levels of communal orientation would be associated with greater life satisfaction and family satisfaction among students providing informal care.

\section{Method}

This cross-sectional study is part of a larger mixed-method investigation that we conducted to explore the young carer experience among Canadian postsecondary students. Following approval from our Institutional Research Ethics Boards, participants from two university campuses in Southwestern Ontario were recruited in lectures on campus and emails were sent through course listservs to provide the link to the study and information-consent letter. Participants were directed to the survey by clicking either a "Yes" or "No" checkbox to indicate whether they had read and understood the study information and consented to participate. Participants who clicked No were directed to the end of the survey. To ensure privacy and confidentiality, all data were de-identified, and researchers did not collect or use internet protocol (IP) addresses or other information that could link participants to their computer or electronic device. All participants, whether they finished the survey or not, were given the option to enter a lottery draw for one of four Starbucks e-gift cards valued at CAD\$25 each.

Of the 148 students who responded, 137 participants completed the survey. The levels of schooling reported were some high school $(0.7 \%)$, high school graduate $(35.6 \%)$, some college $(0.7 \%)$, college graduate $(3.4 \%)$, some university $(55.7 \%)$, university graduate $(3.7 \%)$, and some graduate school $(0.7 \%)$. Students reported majors were mostly from the social sciences, with recreation and leisure (44), human development (22), and psychology (19) the most common. Unfortunately, due to the small sample size in this exploratory study, specific ethnic minorities were not well represented, and there were no analyses of cultural or gender differences among 
students and their caregiving experiences. The survey took approximately 20 minutes to complete using the Qualtrics online platform and consisted of scales and questions assessing six domains: demographics, degree of informal care provision, relationship orientation, benefitfinding, coping, and family and life satisfaction.

\section{Measures}

\section{Demographic information and degree of informal care}

Age was determined by asking participants to select their current age from a drop-down list (17 years or younger to 29 or older). To assess gender, participants were asked to identify whether they were male, female, transgender: male to female, transgender: female to male, or another gender that was not mentioned, with the last option prompting a text entry response. Response options for the variable whether born in Canada were either born in Canada or born outside of Canada.

Given the general dearth of awareness of young carers in Canada and that young carers are considered a "hidden population" who often lack social recognition and struggle with selfidentification (Ali et al., 2013; Banks et al., 2002), we did not ask students to self-identify as young carers or caregivers. Instead, we widened our inclusion criteria to recruit both caregivers and non-caregivers for the study and analyzed caring across a continuum using an informal care typology (Jegermalm, 2006). Thus, we were able to capture the dynamic nature of informal care and subsequently discovered many students who may not have self-identified as young carers. Participants were asked if they "help, on a regular basis (at least once a week), someone close to them who lives either in or outside of the participant's household." Participants were then asked which activities they assist with. These questions focused on seven caring tasks with examples from Jegermalm's (2006) informal care typology: keeping company (e.g., visiting someone, sitting with them), keeping an eye on someone (e.g., checking that everything is alright, regular phone contact), personal care (e.g., dressing, bathing, feeding, using the toilet, giving medication), housework (e.g., preparing meals, cleaning, shopping, laundry), paperwork (e.g., filling in forms, dealing with bills, banking), taking out (e.g., taking out for a drive or a walk), gardening or household repairs, and other (e.g., participants could specify). These were then categorized into four categories: 1) personal care (whether in combination with other caring tasks or not), 2) keeping company and/or keeping an eye on only, 3) practical help (any com bination of housework, paperwork, taking out gardening, etc.) and keeping company and keeping an eye on, and 4) practical help only. Students who reported provision of care anywhere along this continuum were coded as care_home (caregiving provided in the household), care_out (caregiving outside of the household), and the total number of young carers were re-coded as care_any (care_home care_out). The online survey made it possible for participants to report care provision both inside and outside the household. To obtain a sense of how many students had an early caregiving experience before starting their postsecondary studies, participants were also asked if they believed there was a point during their childhood (before the age of 17) when they 
may have identified as a young carer. Response options for this question were yes, no, and maybe.

\section{Communal orientation}

The Communal Orientation Scale (COS), developed by Clark et al. (1987), was used to assess the extent to which students typically behave in a communal fashion in close relationships, as well as the extent to which a per son expects others to behave in a communal fashion toward them (e.g., "It bothers me when other people neglect my needs"; "I often go out of my way to help another person"). The 14-item scale was scored on a 7-point Likert scale ( $1=$ extremely uncharacteristic of me to $7=$ extremely characteristic of me), with five of the items reverse scored $(\alpha=.75)$. The COS has demonstrated adequate psychometric properties with both students and informal caregivers. In its use with a sample of 561 college students, $\alpha=.78$ (Clark et al., 1987), and $\alpha=.70$ in Williamson \& Schulz's (1990) sample of 174 older caregivers.

\section{Benefit-finding}

The 19-item Benefit Finding subscale (BFS), which emerged from Mohr et al.'s (1999) study on patients with MS, was modified in Pakenham's (2005) research on informal carers of patients with MS. For the present study, eight items with the highest factor loadings from Pakenham's (2005) study were chosen to shorten the 19-item subscale. Students rated the extent to which they agreed with statements on a scale ranging from 1 (strongly disagree) to 5 (strongly agree). Item stems were slightly modified from “... (name of care recipient) ... 's MS has ...” to "Caregiving has ..." to better reflect a broader range of caregiving experiences (e.g., "Caregiving has helped me be closer to my family"; "Caregiving has helped me be a better friend"). By using a skip-logic function in the survey, these questions were only asked of respondents who reported they were currently providing some level of informal care $(\alpha=.84)$. The internal reliability coefficients of the BFS were similarly high in both the Mohr et al. (1999) study $(\alpha=.84)$ and in Pakenham's (2005) research $(\alpha=.86-.87)$.

\section{Coping strategies}

Respondents were asked to think of something stressful relating to school (i.e., studying for an important test, working on a group project, writing a paper, et cetera), and the ways in which they have been coping with that stress. Coping was assessed with five subscales: Use of Emotional Support ("I've been getting emotional support from others"; "I've been getting comfort and understanding from someone"), Use of Instrumental Support ("I've been getting help and advice from other people"; "I've been trying to get advice or help from other people about what to do"), Active Coping ("I've been concentrating my efforts on doing something about the situation I'm in"; "I've been taking action to try to make the situation better"), Planning ("I've been trying to come up with a strategy about what to do; "I've been thinking hard about what steps to take"), and Acceptance ("I've been accepting the reality of the fact that it has happened"; "I've been learning to live with it") from the Brief COPE (Carver, 1997). 
Items are on a 4-point Likert-type scale that ranges from "I haven't been doing this at all" (1) to "I've been doing this a lot" (4). The subscales chosen had high factor loadings consistent with previous research findings that caregivers consider these scales critical for their wellbeing (Kimemia, Asner-Self \& Daire, 2011). An analysis showed the items within the subscales were highly correlated with a p value of .01: Emotional Support $(r=.638)$, Instrumental Support $(r=$ $.713)$, Active Coping $(r=.512)$, Planning $(r=.548)$, and Acceptance $(r=.402)$.

\section{Life satisfaction}

The Satisfaction with Life Scale (SWLS), developed by Diener, Emmons, Larsen, and Griffin (1985), measured the levels of life satisfaction among students. Participants were asked to agree or disagree with five statements (e.g., "In most ways my life is close to my ideal"; "The conditions of my life are excellent") using a 1 - to 7 -point scale $(1=$ strongly disagree, $7=$ strongly agree). In the present study, the reliability of this scale was $\alpha=.90$. In a sample of 176 undergraduates, the coefficient alpha was .87 (Diener et al., 1985).

\section{Family satisfaction}

To measure family satisfaction, five items were used from the Extended Satisfaction with Life Scale (ESWLS), developed by Alfonso, Allison, Rader and Gorman (1996). Students were asked to agree or disagree with five statements (e.g., "I am satisfied with my family life"; "So far I have gotten the important things I want from my family life") using a 1- to 7-point scale (1 strongly disagree, 7 strongly agree). The items measuring family satisfaction had a high reliability $(\alpha=.97)$. The family satisfaction subscale also demonstrated strong reliability and validity in Alfonso et al.'s (1996) study of the psychometric properties of the ESWLS $(\alpha=.96)$.

\section{Statistical Analyses}

Descriptive statistics were calculated for all variables in the regression analysis. Regression analysis was used to test the association of communal orientation, benefit-finding, life satisfaction, and family satisfaction in a sample of young carers while controlling for a variety of relevant demographic and survey process-related factors. Control variables of age, gender, and whether born in Canada, and potential mediators (use of emotional support, use of instrumental support, active coping, planning, and acceptance), were added in the regression models.

PROCESS SPSS macro was used to test a mediation model to determine the extent to which a mediating coping variable may help to explain the association between communal orientation (the focal variable) and benefit-finding (the outcome variable) (Figure 1) (Preacher \& Hayes, 2008). Bootstrapping was used in conjunction with this method to create a reference distribution, which was subsequently used for confidence interval estimation and significance testing (Preacher \& Hayes, 2008). 


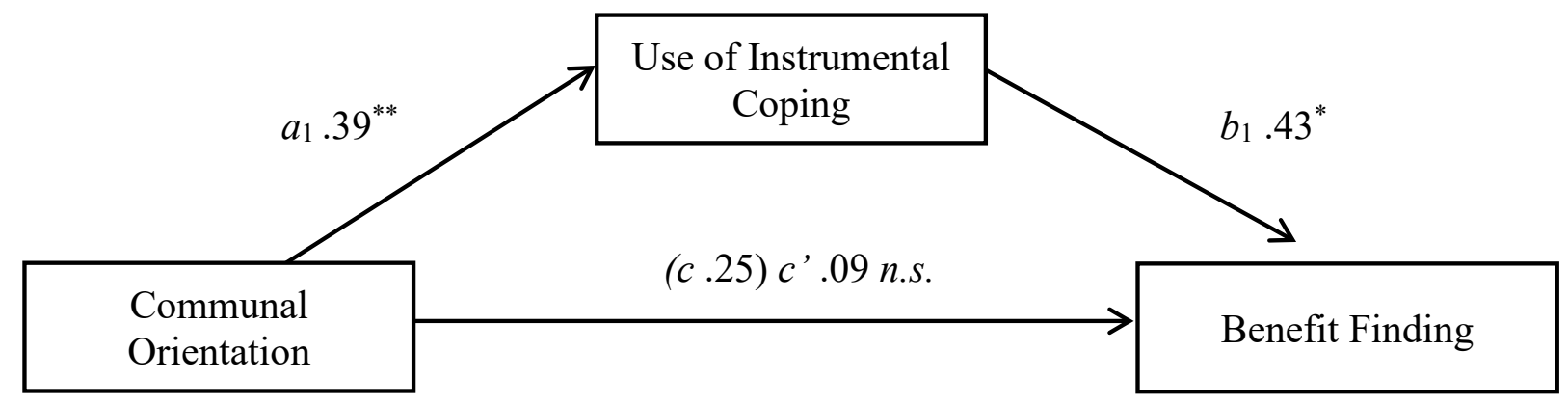

Figure 1. Model of the direct and indirect effects of communal orientation on benefit finding mediated by use of instrumental support. $* \mathrm{p}<.05,{ }^{*} \mathrm{p}<.01, * * * \mathrm{p}<.001$

\section{Results}

Of the 137 participants age $17-29,64(46.7 \%)$ reported they were currently providing some degree of informal care for a family member or close friend. The average age of caregivers was 20.28 years $(\mathrm{SD}=2.45), 80.6 \%$ of caregivers were female, and $79.4 \%$ were born in Canada. One hundred and two respondents $(74.5 \%)$ identified their ethnicity as white; the three next highest represented ethnicities were South Asians $(n=9)$, Chinese $(n=6)$, and Black/African Canadian $(n=6)$. Most participants were born in Canada, with only 24 who reported being Canadian by naturalization.

The ethno-racial and gender makeup of the sample is an accurate reflection of the current Canadian university demographic landscape - in a recent survey of 7,998 Canadian students, $71 \%$ of respondents identified as female and $69 \%$ identified as Caucasian or white (National Survey of Student Engagement, 2018). The sample is also consistent with young carer research in Canada, Australia, and the United Kingdom that demonstrates how caregiving responsibilities among young people run along gendered lines, with female young carers often outnumbering male young carers, as is demonstrated in other studies (Stamatopoulos, 2018, 2015a).

Six participants mistook questions about informal care with care relating to their work or volunteering (e.g., working within developmental services, or with older adults) and, as such, were not included in the analyses. Of the students who retrospectively considered their experiences as consistent with the definition of a young carer $(n=126), 30(23.8 \%)$ participants responded "yes" to whether they had provided some level of caregiving before the age of 17, and $18(14.3 \%)$ responded with "maybe." These students who identified having a young carer experience prior to their postsecondary studies were not included in the regression analyses. The rationale for this exclusion was that the immediacy of a current caregiving situation would provide a clearer picture of the experience of caring while coping with school-related stressors, which was the focus for the present study. For a list of descriptive statistics on all the variables in the model, see Table 1. 
Table 1: Means and Frequencies for Demographic, Communal Orientation, Benefit Finding, Coping and Well-being Variables Among Current Young Carers $(n=64)$

\begin{tabular}{lrr}
\hline Variable & $M / \%$ & \multicolumn{1}{l}{$S D$} \\
\hline Demographics & & \\
$\quad$ Age $(17-29)$ & 20.28 & 2.45 \\
Gender (female) & 80.60 & -- \\
$\quad$ Born in Canada & 79.40 & -- \\
Communal Orientation & 5.06 & 0.90 \\
Benefit Finding & 4.07 & 0.60 \\
Coping & & \\
$\quad$ Emotional Support & 2.82 & 0.82 \\
$\quad$ Instrumental Support & 2.81 & 0.86 \\
$\quad$ Active Coping & 2.96 & 0.69 \\
$\quad$ Planning & 2.96 & 0.71 \\
$\quad$ Acceptance & 3.04 & 0.63 \\
Wellbeing & & \\
Life Satisfaction & 4.80 & 1.29 \\
Family Satisfaction & 5.32 & 1.62 \\
\hline
\end{tabular}

Regression analyses showed only specific control variables in each model were significantly associated with the outcome variables. Participants who rated themselves as higher in communal orientation reported higher levels of benefit-finding (Table 2, Model 1). Greater use of instrumental support was also associated with higher ratings of benefit-finding (Table 2, Model 2). Higher levels of communal orientation were negatively associated with life satisfaction (Table 3, Model 2). Finally, among the young carers who reported higher levels of communal orientation there was a negative association with family satisfaction (Table 4, Model 2). 
Table 2. Unstandardized Coefficients for Regression Models Showing Association of Demographics, Communal Orientation, and Coping strategies with Benefit finding.

\begin{tabular}{lccccc}
\hline & \multicolumn{2}{c}{ Model 1 } & & \multicolumn{2}{c}{ Model 2 } \\
\cline { 2 - 3 } \cline { 5 - 6 } Independent Variables & B & SE & & B & SE \\
\hline Constant & $3.09^{* * *}$ & 0.53 & & $1.98^{* *}$ & .64 \\
Demographics & & & & & \\
$\quad$ Age & -0.01 & 0.04 & & 0.05 & 0.04 \\
$\quad$ Gender (Female $=1)$ & 0.12 & 0.23 & & 0.08 & 0.22 \\
$\quad$ Born in Canada (yes $=1)$ & -0.31 & 0.23 & & -0.15 & 0.22 \\
$\quad$ Communal orientation & $0.25^{* *}$ & 0.09 & & 0.09 & 0.11 \\
Coping & & & & \\
$\quad$ Emotional Support & -- & -- & & -0.13 & 0.14 \\
$\quad$ Instrumental Support & -- & -- & $0.43^{* *}$ & 0.17 \\
$\quad$ Active Coping & -- & -- & 0.05 & 0.16 \\
$\quad$ Planning & -- & -- & 0.07 & 0.15 \\
$\quad$ Acceptance & -- & -- & 0.09 & 0.14 \\
\hline Adj. $\mathrm{R}^{2}$ & 0.09 & & & 0.25 & \\
$* p<.05, * * p<.01, * * * p<.001$ & & & & \\
\end{tabular}

Table 3. Unstandardized Coefficients for Regression Models Showing Association of Demographics, Communal Orientation, and Coping strategies with Life Satisfaction.

\begin{tabular}{|c|c|c|c|c|}
\hline \multirow[b]{2}{*}{ Independent Variables } & \multicolumn{2}{|c|}{ Model 1} & \multicolumn{2}{|c|}{ Model 2} \\
\hline & B & SE & B & SE \\
\hline Constant & $7.91^{* * *}$ & 1.17 & $7.62^{* * *}$ & 1.52 \\
\hline \multicolumn{5}{|l|}{ Demographics } \\
\hline Age & -0.01 & 0.08 & -0.06 & 0.09 \\
\hline Gender $($ Female $=1)$ & 0.29 & 0.50 & 0.21 & 0.52 \\
\hline Born in Canada (yes = 1) & -0.66 & 0.21 & -0.65 & 0.52 \\
\hline Communal orientation & $-0.44^{*}$ & 0.21 & $-0.81^{* * *}$ & 0.26 \\
\hline \multicolumn{5}{|l|}{ Coping } \\
\hline Emotional Support & -- & -- & 0.42 & 0.33 \\
\hline Instrumental Support & -- & -- & 0.17 & 0.39 \\
\hline Active Coping & -- & -- & 0.56 & 0.38 \\
\hline Planning & -- & -- & -0.22 & 0.36 \\
\hline Acceptance & -- & -- & -0.17 & 0.33 \\
\hline $\begin{array}{l}\text { Adj. } \mathrm{R}^{2} \\
* p<.05, * * p<.01, * * * p<.00\end{array}$ & 0.09 & & 0.15 & \\
\hline
\end{tabular}

Areguy, Mock, Breen, van Rhijn, Wilson, \& Lero, 2019 
Table 4. Unstandardized Coefficients for Regression Models Showing Association of Demographics, Communal Orientation, and Coping strategies with Family Satisfaction.

\begin{tabular}{|c|c|c|c|c|}
\hline \multirow[b]{2}{*}{ Independent Variables } & \multicolumn{2}{|c|}{ Model 1} & \multicolumn{2}{|c|}{ Model 2} \\
\hline & B & SE & $\mathbf{B}$ & SE \\
\hline Constant & $9.16^{* * *}$ & 1.47 & $7.87^{* * *}$ & 1.83 \\
\hline \multicolumn{5}{|l|}{ Demographics } \\
\hline Age & $-0.18^{*}$ & 0.10 & -0.03 & 0.11 \\
\hline Gender $($ Female $=1)$ & 0.27 & 0.63 & 0.04 & 0.63 \\
\hline Born in Canada (yes $=1$ ) & -0.52 & 0.65 & -0.24 & 0.62 \\
\hline Communal orientation & $-0.54^{*}$ & 0.26 & $-0.81^{* *}$ & 0.31 \\
\hline \multicolumn{5}{|l|}{ Coping } \\
\hline Emotional Support & -- & -- & -0.21 & 0.39 \\
\hline Instrumental Support & -- & -- & 0.76 & 0.47 \\
\hline Active Coping & -- & -- & 0.38 & 0.45 \\
\hline Planning & -- & -- & 0.37 & 0.43 \\
\hline Acceptance & -- & -- & -0.61 & 0.39 \\
\hline $\begin{array}{l}\text { Adj. } \mathrm{R}^{2} \\
* p<.05, * * p<.01, * * * p<.00\end{array}$ & 0.09 & & 0.23 & \\
\hline
\end{tabular}

Mediation analysis was used to determine the extent to which the association of communal orientation with benefit-finding was explained by the coping variable, use of instrumental support (Preacher \& Hayes, 2008). The indirect effect through instrumental support was statistically significant (point estimate $=0.17, \mathrm{SE}=0.094, p<0.05$, suggesting those with greater communal orientation were more able to find benefit in their role because they were also reaching out to others for help and advice (instrumental support).

\section{Discussion}

The present study was designed to determine the association of communal orientation and coping variables with young student carers' ability to engage in benefit-finding and enhanced satisfaction with life and family. Among students currently in an informal caregiving situation, communal orientation was positively associated with benefit-finding. The findings suggest benefit-finding is a strong predictor for both positive and adaptive outcomes, adding to the evidence that benefit-finding is an important psychological adjustment for caregivers (Davis et al., 1998; Mock \& Boerner, 2010; Pakenham et al., 2006). The mediation analysis revealed the use of instrumental support mediated the association between communal orientation and benefitfinding. This is supported by research that has found social support to be a strong predictor of adjustment in young carers (Pakenham et al., 2007). This is especially important given that the majority of formal and informal support services focus on care recipients and often fail to recognize young carers in family systems. 
One interesting finding was that communal orientation was negatively associated with life and family satisfaction. This finding is contrary to studies in the adult caregiving literature which have suggested that communal orientation acts as a buffer for caregiver distress and burden (VanYperen et al.,1992; Williamson \& Schulz, 1990). Why would communally oriented young carers who attend postsecondary education experience strain from the caregiving relationship? For most undergraduates, attending a postsecondary institution signals a shift away from their childhood home and their family. However, for students in a caring role or those who suddenly learn of a caregiving situation back at home, this may create ambivalence and stress. Thus, it is possible a higher level of communal orientation may amplify this ambivalence and negatively impact overall life and family satisfaction. It is common for young carers to feel a push-and-pull between their idealized life and their caregiver reality, and not being available to help in a caring capacity can lead to feelings of anger, guilt, and loss (Charles et al., 2012). This conflict may potentially explain why negative outcomes and a decreased ability to cope with school-related stress may be compounded for undergraduate young carers high in communal orientation, as they may be unable to provide the care they feel responsible for providing while attending university.

These findings suggest promising areas for future research. One important area for further inquiry is the examination of communal orientation as a possible resource for young carers and its potential usefulness as a buffer for negative health and social outcomes. The potential negative impacts of communal orientation among young carers should also be further explored; the dimensions of burnout, specifically self-efficacy, and other wellbeing outcomes should be measured concurrently to determine the nature of the associations between these factors. Future studies might also explore whether caregiving situations cause young carers to become more communally orientated, or if higher rates of communal orientation are common among young people who take on extra responsibilities within a family. Clarity regarding the direction and nature of this association would allow for a more comprehensive understanding of the young carer experience and may be helpful for the development of supports for young carers.

Second, based on the result of benefit-finding being a major resource and buffer for young carers attending school, future studies on the role of cognitive appraisals and coping methods among young carers are recommended. But in addition to individual-level factors, it is important to acknowledge situational stressors that young carers experience. Focusing on cognitive appraisals without attending to situational realities can be akin to "victim-blaming" because it puts the onus on the young person to "adjust" rather than addressing the social and structural issues that create challenges and risks for young people (Breen, Bell, \& Tassiuk, 2017; Breen \& McLean, 2017). The reality is that some caregiving experiences may be especially difficult and there may be little or no "benefit" to be found (Breen \& McLean, 2016; Mock \& Boerner, 2010). The potentially positive aspects of caregiving may be eclipsed if a situation poses real risks to young peoples' educational and employment outcomes as well as their social and emotional wellbeing (Charles et al., 2012; Stamatopoulos 2018). 
The current study findings point to both positive and negative impacts young carers attending postsecondary experience; however, findings of potential benefits derived from caregiving must not preclude attending to their needs and understanding their experiences, and instead guide examinations into young carers' experiences, the meaning they make of these experiences in the context of their caregiving relationships, and the long-term impacts on young carers' social, emotional, physical, and employment outcomes. Future directions for research may also consider the differences between types of care provided (e.g., the differences between caring for a grandparent and caring for a sibling) and how caregiving changes over time and how the transition to caregiving affects health and well-being outcomes.

Investigations around young carer age, care circumstances, and degree of care provision should be careful not to draw attention away from the lived-experiences of young carers. The complexity of young carers' experiences calls for mindful approaches that acknowledge their needs without losing sight of the larger issue of why such care is being provided by young people (Charles et al., 2012). Moving forward, studies must be rooted in the lived-experiences of young carers. As the number of young carers continue to grow, it will become increasingly important to recognize young carers in our postsecondary institutions and to provide flexible and effective resources to support them. 


\section{References}

Adlaf, E. M., Demers, A., \& Gliksman, L. (2005). Canadian Campus Survey 2004, 129. Retrieved from http://www.camh.net/research/population_life_course.html

Adlaf, E. M., Gliksman, L., Demers, A.a, \& Newton-Taylor, B. (2001). The prevalence of elevated psychological distress among Canadian undergraduates: findings from the 1998 Canadian Campus Survey. Journal of American College Health, 50(2), 67-72. doi:10.1080/ 07448480109596009

Affleck, G., \& Tennen, H. (1996). Construing benefits from adversity: Adaptational significance and dispositional underpinnings. Journal of Personality, 64(4), 899-922. doi: 10.1111/j.1467-6494.1996.tb00948.x

Aldridge, J., \& Becker, S. (1993). Children who care: Inside the world of young carers. Loughborough: Young Carers Research Group.

Alfonso, V. C., Allison, D. B., Rader, D. E., \& Gorman, B. S. (1996). The extended satisfaction with life scale: Development and psychometric properties. Social Indicators Research, 38(3), 275-301. doi:10.1007/BF00292049

Ali, L., Ahlström, B. H., Krevers, B., Sjöström, N., \& Skärsäter, I. (2013). Support for young informal carers of persons with mental illness: a mixed-method study. Issues in Mental Health Nursing, 34(8), 611-618. doi:10.3109/01612840.2013.791736

Andreouli, E., Skovdal, M., \& Campbell, C. (2013). "It made me realise that I am lucky for what I got": British young carers encountering the realities of their African peers. Journal of Youth Studies, 16(8), 1038-1053. doi:10.1080/13676261.2013.772574

Armistead, L., Klein, K., \& Forehand, R. (1995). Parental physical illness and child functioning. Clinical Psychology Review, 15(5), 409-422. doi:10.1016/02727358(95)00023-I

Banks, P., Cogan, N., Riddell, S., Deeley, S., Hill, M., \& Tisdall, K. (2002). Does the covert nature of caring prohibit the development of effective services for young carers? British Journal of Guidance and Counselling, 30, 229 -246. doi:10.1080/030698802100002281

Barry, M. (2011). 'I realised that I wasn't alone': the views and experiences of young carers from a social capital perspective. Journal of Youth Studies, 14(5), 523-539. doi:10.1080/ 13676261.2010 .551112

Battams, N. (2013), "Young caregivers in Canada," Fascinating Families 59, The Vanier Institute of the Family. Retrieved from http://vanierinstitute.ca/wpcontent/uploads/2015/11/FFAM_2013-11-00_Young-Carergivers-in-Canada.pdf

Becker, S. (2007). Global perspectives on children's unpaid caregiving in the family. Global Social Policy, 7, 23-50. doi:10.1177/1468018107073892

Becker, S. (1995). Young carers in Europe: An exploratory cross-national study in Britain, France, Sweden and Germany. Loughborough, Leics: Young Carers Research Group, Loughborough University.

Breen, A. V., Bell, J., \& Tassiuk, E. (2017). Research for resilience and reconciliation. Paper presented at the Pathways to Resilience IV Conference, Cape Town, South Africa.

Breen, A. V., \& McLean, K. C. (2017). The intersection of personal and master narratives: Is redemption for everyone? In B. Schiff, E. McKim, \& S. Patron (Eds.), Life and narra- tive: 
The risks and responsibilities of storying experience (pp. 197-213). Oxford, UK: Oxford University Press.

Brown, S. L. (2007). Health effects of caregiving: Studies of helping behavior needed! Alzheimer's Care Today, 8(3), 235-246.

Carver, C. S. (1997). You want to measure coping but your protocol's too long: Consider the Brief COPE. International Journal of Behavioral Medicine, 4(1), 92-100. doi:10.1207/ s15327558ijbm0401_6

Carver, C. S., \& Vargas, S. (2012). Stress, Coping, and Health. In The Oxford Handbook of Health Psychology Oxford University Press.

Cassidy, T., \& Giles, M. (2013). Further exploration of the Young Carers Perceived Stress Scale: Identifying a benefit-finding dimension. British Journal of Health Psychology, 18(3), 642-655. doi:10.1111/bjhp.12017

Cassidy, T., Giles, M., \& McLaughlin, M. (2014). Benefit finding and resilience in child caregivers. British Journal of Health Psychology, 19(3), 606-618. doi:10.1111/bjhp.12059

Charles, G., Marshall, S., \& Stainton, T. (2010). Demographics profiles and initial results from the British Columbia Young Carers Study. Relational Child and Youth Care Practice, 23(4), 64-67.

Charles, G., Stainton, T., \& Marshall, S. (2012). Young carers in Canada: The hidden costs and benefits of young caregiving. Ottawa: Vanier Institute of the Family. Retrieved from http://vanierinstitute.ca/wp-content/uploads/2015/12/CFT_2012-07-00_EN.pdf

Clark, M. S., \& Finkel, E. J. (2005). Willingness to express emotion: The impact of relationship type, communal orientation, and their interaction. Personal Relationships, 12(2), 169180. doi:10.1111/j.1350-4126.2005.00109.x

Clark, M. S., \& Mills, J. (1979). Interpersonal attraction in exchange and communal relationships. Journal of Personality and Social Psychology, 37(1), 12-24.

Clark, M. S., Mills, J. (2012). Communal (and exchange) relationships. In Van Lange, P. A. M., Kruglanski, A. W., Higgins, E. T. (Eds.), Handbook of theories of social psychology (pp. 232-250). Thousand Oaks, CA: Sage Publications.

Clark, M. S., Ouellette, R., Powell, M. C., \& Milberg, S. (1987). Recipient's mood, relationship type, and helping. Journal of Personality and Social Psychology, 53(1), 94-103. doi: 10.1037/0022-3514.53.1.94

Cohen, C. A., Colantonio, A., \& Vernich, L. (2002). Positive aspects of caregiving: Rounding out the caregiver experience. International Journal of Geriatric Psychiatry, 17(2), 184188. doi:10.1002/gps.561

Cree, V. E. (2003). Worries and problems of young carers: issues for mental health. Child \& Family Social Work, 8(4), 301-309. doi:10.1046/j.1365-2206.2003.00292.x

Davis, C. G., Nolen-Hoeksema, S., \& Larson, J. (1998). Making sense of loss and benefiting from the experience: two construals of meaning. Journal of Personality and Social Psychology, 75(2), 561-574. doi:10.1037/0022-3514.75.2.561

Diener, E. D., Emmons, R. A., Larsen, R. J., \& Griffin, S. (1985). The satisfaction with life scale. Journal of Personality Assessment, 49(1), 71-75.

doi:10.1207/s15327752jpa4901_13 
Early, L., Cushway, D., \& Cassidy, T. (2006). Perceived stress in young carers: Development of a measure. Journal of Child and Family Studies, 15(2), 165-176. doi:10.1007/s10826005-9011-z

Fast, J. (2015). Caregiving for older adults with disabilities: Present costs, future challenges. IRPP Study, 58. Retrieved from http://irpp.org/wp-content/uploads/2015/12/studyno58.pdf

Fauth, E., Hess, K., Piercy, K., Norton, M., Corcoran, C., Rabins, P., ... ' Tschanz, J. (2012). Caregivers' relationship closeness with the person with dementia predicts both positive and negative outcomes for caregivers' physical health and psychological wellbeing. Aging \& Mental Health, 16(6), 699-711.

Frank, J. (1995). Couldn't care more: A study of young carers and their needs. London, UK: Children's Society.

Grossman, F.K. (1972). Brothers and Sisters of Retarded Children: An Exploratory Study. Syracuse, NY: Syracuse University Press.

Hill, S. (1999). The physical effects of caring on children. The Journal of Young Carers Work, 3(1), 6-7.

House, J. S., Landis, K.R., Umberson, D. (1988). Social relationships and health. Science, 241(4865), 540-545.

Jegermalm, M. (2006). Informal care in Sweden: a typology of care and caregivers. International Journal of Social Welfare, 15(4), 332-343. doi:10.1111/j.1468- 2397.2006.00400.x

Jones D. C., Vaughan K. (1990). Close friendships among senior adults. Psychology and Aging, 5, 451-457.

Kim, Y., Schulz, R., \& Carver, C. S. (2007). Benefit-finding in the cancer caregiving experience. Psychosomatic Medicine, 69(3), 283-291. doi:10.1097/PSY.0b013e3180417cf4

Kimemia, M., Asner-Self, K. K., \& Daire, A. P. (2011). An exploratory factor analysis of the Brief COPE with a sample of Kenyan caregivers. International Journal for the Advancement of Counselling, 33(3), 149-160. doi:10.1007/s10447-011-9122-8

Le, B. M., Impett, E. A., Kogan, A., Webster, G. D., \& Cheng, C. (2013). The personal and interpersonal rewards of communal orientation. Journal of Social and Personal Relationships, 30(6), 694-710. doi:10.1177/0265407512466227

McCall M. (1995). Orientation, outcome, and other-serving attributions. Basic and Applied Social Psychology, 17(1), 49-64. doi:10.1207/s15324834basp1701\&2_3

Miller, P. (2012). Do Australian teenagers work? Why we should care. Feminist Economics, 18(4), 1-24. doi:10.1080/13545701.2012.731514

Mills, J., \& Clark, M. S. (1982). Exchange and communal relationships. Review of Personality and Social Psychology, 3, 121-144.

Mock, S., \& Boerner, K. (2010). Sense making and benefit finding among patients with amyotrophic lateral sclerosis and their primary caregivers. Journal of Health Psychology, 15, 115-121. doi:10.1177/1359105309344897

Mohr, D. C., Dick, L. P., Russo, D., Pinn, J., Boudewyn, A. C., Likosky, W., \& Goodkin, D. E. (1999). The psychosocial impact of multiple sclerosis: Exploring the patient's perspective. Health Psychology, 18(4), 376. doi:10.1037//0278-6133.18.4.376 
Moore, T., McArthur, M., \& Noble-Carr, D. (2011). Different but the same? Exploring the experiences of young people caring for a parent with an alcohol or other drug issue. Journal of Youth Studies, 14(2), 161-177. doi:10.1080/13676261.2010.522561

National Survey of Student Engagement. (2018). NSSE 2018 overview. Bloomington, IN: Indiana University Center for Postsecondary Research.

Pakenham, K. I. (2005). The positive impact of multiple sclerosis (MS) on carers: associations between carer benefit finding and positive and negative adjustment domains. Disability and Rehabilitation, 27(17), 985-997. doi:10.1080/09638280500052583

Pakenham, K. I., Bursnall, S., Chiu, J., Cannon, T., \& Okochi, M. (2006). The psychosocial impact of caregiving on young people who have a parent with an illness or disability: Comparisons between young caregivers and noncaregivers. Rehabilitation Psychology, 51(2), 113-126. https://doi.org/10.1037/0090-5550.51.2.113

Pakenham, K. I., Chiu, J., Bursnall, S., \& Cannon, T. (2007). Relations between social support, appraisal and coping and both positive and negative outcomes in young carers. Journal of Health Psychology, 12(1), 89-102. doi:10.1177/1359105307071743

Pakenham, K. I., Sofronoff, K., \& Samios, C. (2004). Finding meaning in parenting a child with Asperger syndrome: Correlates of sense making and benefit finding. Research in Developmental Disabilities, 25(3), 245-264. doi:10.1016/j.ridd.2003.06.003

Park, C. L., \& Folkman, S. (1997). Meaning in the context of stress and coping. Review of General Psychology, 1(2), 115-144. doi:10.1037/1089-2680.1.2.115

Pinquart, M., \& Sorensen, S. (2003a). Associations of stressors and uplifts of caregiving with caregiver burden and depressive mood: A meta-analysis. Journals of Gerontology, Series B, Psychological Sciences and Social Sciences, 58(2), P112P128. doi:10.1093/geronb/58.2.P112

Pinquart, M., \& Sorensen, S. (2003b). Differences between caregivers and noncaregivers in psychological health and physical health: A meta-analysis. Psychology and Aging, 18(2), 250-267. doi:10.1037/0882-7974.18.2.250

Preacher, K. J., and Hayes, A. F. (2008). Asymptotic and resampling strategies for assessing and comparing indirect effects in multiple mediator models. Behavior Research Methods, 40, 879-891. doi:10.3758/BRM.40.3.879

Remtulla, Y., Charles, G., \& Marshall, S. (2012). An analysis of responsibility, attachment security, and relationship efficacy among young carers. Relational Child and Youth Care Practice, 25(2), 49.

Rose, H. D., \& Cohen, K. (2010). The experiences of young carers: A meta-synthesis of qualitative findings. Journal of Youth Studies, 13(4), 473-487. doi:10.1080/ 13676261003801739

Schulz, R., \& Sherwood, P. (2008). Physical and mental health effects of family caregiving. The American Journal of Nursing, 108(9 Suppl), 23-27. doi:10.1097/01.NAJ.0000336406. $45248.4 \mathrm{c}$

Schulz, R., O'Brien, A. T., Bookwala, J., \& Fleissner, K. (1995). Psychiatric and physical morbidity effects of dementia caregiving: prevalence, correlates, and causes. The Gerontologist, 35(6), 771-791. doi:10.1093/geront/35.6.771

Sinha, M. (2013). Portrait of caregivers, 2012. Statistics Canada, (89), 1-21. doi:10.1162/ISEC 
Skovdal, M., \& Andreouli, E. (2011). Using identity and recognition as a framework to understand and promote the resilience of caregiving children in western Kenya. Journal of Social Policy, 40(03), 613-630. doi:10.1017/S0047279410000693

Skovdal, M., Ogutu, V. O., Aoro, C., \& Campbell, C. (2009). Young carers as social actors: Coping strategies of children caring for ailing or ageing guardians in Western Kenya. Social Science \& Medicine, 69(4), 587-595. doi:10.1016/j.socscimed.2009.06.016

Smyth, C., Blaxland, M., \& Cass, B. (2011). 'So that's how I found out I was a young carer and that I actually had been a carer most of my life'. Identifying and supporting hidden young carers. Journal of Youth Studies, 14(2), 145-160. doi:10.1080/ 13676261.2010.506524

Stamatopoulos, V. (Forthcoming). Supporting or separate domains? Parentification and young carers in Canada. In L. M. Hooper (Ed.), Parentification: Racial, ethnic, cultural, and contextual influences on culturally tailored assessment and treatment. New York, NY: Springer-Science.

Stamatopoulos, V. (2015a). One million and counting: The hidden army of young carers in Canada. Journal of Youth Studies, 18(6), 809-822. doi:10.1080/13676261.2014.992329

Stamatopoulos, V. (2015b, September). Supporting young carers: a qualitative review of young carer services in Canada. International Journal of Adolescence and Youth, 3843, 1-17. doi:10.1080/02673843.2015.1061568

Taylor, S. E. (1983). Adjustment to threatening events. American Psychologist, 38(11), 11611173. doi:10.1037/0003-066X.38.11.1161

Thomas, N., Stainton, T., Jackson, S., Cheung, W. Y., Doubtfire, S., \& Webb, A. (2003). Your friends don't understand': Invisibility and unmet need in the lives of 'young carers. Child \& Family Social Work, 8(1), 35-46. doi:10.1046/j.1365-2206.2003.00266.x

Thompson, L., \& DeHarpport, T. (1998). Relationships, goal incompatibility, and communal orientation in negotiations. Basic and Applied Social Psychology, 20(1), 33-44. doi: $10.1207 / 15324839851036831$

Truchot, D., \& Deregard, M. (2001). Perceived inequity, communal orientation and burnout: The role of helping models. Work \& Stress, 15(4), 347-356. doi:10.1080/ 02678370110086380

Truchot, D., Keirsebilck, L., \& Meyer, S. (2000). Communal orientation may not buffer burnout. Psychological Reports, 86(3), 872-878. doi:10.2466/pr0.2000.86.3.872

VanYperen, N. W., Buunk, B. P., \& Schaufeli, W. B. (1992). Communal orientation and the burnout syndrome among nurses. Journal of Applied Social Psychology, 22(3), 173-189. doi:10.1111/j.1559-1816.1992.tb01534.x

Vitaliano, P. P., Zhang, J., \& Scanlan, J. M. (2003). Is caregiving hazardous to one's physical health? A meta-analysis. Psychological Bulletin, 129(6), 946-972. doi:10.1037/00332909.129.6.946

Williamson, G. M., \& Schulz, R. (1990). Relationship orientation, quality of prior relationship, and distress among caregivers of Alzheimer's patients. Psychology and Aging, 5(4), 502509. doi:10.1037/0882-7974.5.4.502

Worsham N.L., Compas B.E., Ey S. (1997) Children's coping with parental illness. In A. Wolchik \& I. N. Sandler (Eds.) Handbook of children's coping. Issues in clinical child psychology. Boston, MA: Springer. 